\title{
EFFECT OF NIGELLA SATIVA OIL ON SCHISTOSOMA MANSONI MATURE WORMS IN EXPERIMENTALLY INFECTED MICE
}

\section{By}

\author{
EMAN A. ABOUOUF ${ }^{1 *}$, AZZA M. S. ELHAMSHARY ${ }^{1}$, IBRAHIM M. NAGATI', \\ MAYSA A. ERAKY ${ }^{1}$, ASMAA A. ELKHOLY ${ }^{1}$, AMANY N. IBRAHIM ${ }^{2}$, \\ And GHADA H. OMAR ${ }^{1}$ \\ Departments of Parasitology ${ }^{1}$ and Pharmacology ${ }^{2}$, Faculty of Medicine, \\ Benha University, Egypt ( ${ }^{*}$ Correspondence: emanabououf@yahoo.com)

\section{Abstract}

The chemical drugs are safe and effective being the main tool in controlling schistosomiasis. Referring to the possibility of appearance of drug resistant parasites especially with retreatment regimens in endemic areas, search for new schistosomicidal is essential. Nigella sativa has been extensively studied for its biological activities and therapeutic potentials and shown to possess wide spectrum of activities including antihelminthic and antiprotozoal activities. The present report aimed to investigate the prophylactic and therapeutic effect of Nigella sati$v a$ oil in treatment of Schistosoma mansoni. Nigella sativa oil was administrated orally to $S$. mansoni infected mice in two different doses, a prophylactic dose $(1.14 \mathrm{~g} / \mathrm{kg})$ every day for 2 weeks before infection and a therapeutic dose $(1.14 \mathrm{~g} / \mathrm{kg})$ daily for 4 weeks starting from $2 \mathrm{nd}$ day post infection aiming to investigate its potential therapeutic role. Therapeutic treatment with Nigella sativa oil had a high significant effect on mature worm burden, as the reduction percentage was (57.5\%). Nigella sativa oil in prophylactic and therapeutic doses significantly increased the mean number of dead ova $(14.75 \pm 6.5)$ and $(21.43 \pm 3.64)$ respectively in comparison to control (5.25 \pm 1.71$)$. Nigella sativa oil therapeutic dose had a high reduction effect on ova count in intestinal tissue $(81.45 \%)$ and a moderate reduction on ova count in hepatic tissue $(57.86 \%)$. Prophylactic dose gave a high reduction effect $(78.76 \%)$ on ova count in intestinal tissue. As regard the size of hepatic granuloma, Nigella sativa oil treated group had the highest significant reduction on mean granuloma diameter; the reduction was $26.69 \%$ with marked improvement of hepatic pathology. $N$. sativa oil treated group showed obvious improvement of liver pathology with mild hydrobic degeneration and small sized fibrocellular granuloma accompanied by multiple malformations in both $S$. mansoni adult worms. These results showed that $N$. sativa oil has remarkable effect on mature $S$. mansoni which could be helpful for potentiating Praziquantel effect and thus reducing development of resistance.

Keywords: Nigella sativa, Schistosoma mansoni, mature worms.

\section{Introduction}

Schistosomiasis is a neglected disease that affects approximately 240 million people worldwide (WHO, 2012). The used drugs for treatment of schistosomisasis are Praziquantel (PZQ) and Oxamniquine. However, any parasitic treatment based on the use of a single drug possesses serious concerns regarding the onset of resistance (Castro et al, 2013).

There is an increasing awareness of the therapeutic potentials of natural products and medicinal plants which were considered to be less toxic and free from side effects than synthetic drugs in treating some diseas- es (Queiroz et al, 2009). Larger number of medicinal plants and their purified constituents were thoroughly investigated for medicinal properties, potentials, mechanism of action, safety evaluation and toxicological studies (Salem, 2005). The miracle herb, $\mathrm{Ni}$ gella sativa seeds have been employed as food preservative and a spice (Al-Ali et al, 2008). The chemical composition of the seeds is oil $31-35.5 \%$, protein $16-19.9 \%$ and various chemical composition of fixed and volatile oils (El-Tahir et al, 2006; Nickavar, 2003). Thymoquinone (TQ) is an active chemical component of Nigella sativa essential oil, of which many therapeutic properties 
included (Abdel Hady et al, 2008). Historically, Nigella sativa seeds were prescribed by ancient Egyptian and Greek physician to treat many diseases (Goreja, 2003). Its oil exhibited a wide range of pharmacological activities including anti-inflammatory (Chakra-barty et al, 2003), anti-microbial (Bakathir and Abbas, 2011; Barakat et al, 2013) and anti-oxidant (Bourgou et al, 2012). It has anticestodal and antinematodal properties (Agrawal et al, 1979). N. sativa oil has antiparasitic effect against some protozoal infections as Entamoeba histolytica (Shariff et al, 2011), Trichomonas vaginalis (Tonkal, 2009) and Plasmodium yoelii (Okeola et al, 2011).

This present work aimed to explore the potential role of Nigella sativa oil either therapeutic or prophylactic in treatment of Schistosoma mansoni.

\section{Materials and Methods}

Herbal extract: Nigella sativa oil (Family Ranunculaceae) was obtained as soft gelatin capsules of $450 \mathrm{mg}$ (Pharco-Pharmaceutical, Alexandria). Capsules were opened and oil was dissolved in corn oil (Sharafeldin et al, 2015) to obtain a concentration of $1.14 \mathrm{gm}$ $/ \mathrm{kg}$ (Soliman and El-Shenawy, 2003).

Parasites and animals: Cercariae of Schistosoma mansoni were obtained from infected Biomphalaria alexandrina reared and maintained at Schistosome Biological Supply Program (SBSP), Theodor Bilharz Research Institute. 120 laboratory-bred male Swiss albino mice, CD1 bred, were used. All mice were infected with $60 \pm 10 \mathrm{~S}$. mansoni cercariae suspended in $0.2 \mathrm{ml}$ water via subcutaneous injection.

Experimental design: Infected mice were divided into 6 groups. G1: Non-infected non-treated. G2: Infected non-treated. G3: Infected and treated with $N$. sativa oil $(1.14 \mathrm{~g} / \mathrm{kg})$ daily for 2 weeks before infection, (prophylactic).G4: Infected and treated with Praziquantel $(500 \mathrm{mg} / \mathrm{Kg})$ for 2 successive days at $6^{\text {th }}$ week of infection. G5: Infected and treated with $N$. sativa oil $(1.14 \mathrm{~g} / \mathrm{kg})$ daily for 4 weeks starting from $2^{\text {nd }}$ day post infection,(therapeutic group).Group 6: Infected and treated with $N$. sativa oil $(1.14 \mathrm{~g}$ $\mathrm{kg}$ ) daily for 4 weeks starting from $2^{\text {nd }}$ day post infection and Praziquantel $(500 \mathrm{mg} / \mathrm{Kg}$ ) for 2 successive days at $6^{\text {th }}$ week of infection. All mice were sacrificed after the $8^{\text {th }}$ week post infection.

Evaluation of $N$. sativa oil schistosomicidal effect: Worm Burden: Adult schistosome recovery was assessed by porto-mesenteric perfusion technique according to the method of Duvall and DeWitt (Duvall and Dewitte, 1967).

Oogram pattern: The pattern (Pellegrino et $a l, 1962)$ evaluated degree of ova maturity and viability reflected the drug action affecting oviposition and maturation. After perfusion, three fragments (each $1 \mathrm{~cm}$ in length) of small intestine were cut longitudinally, rinsed in saline, slightly dried on filter paper and then compressed between two glass slides .One hundred eggs were counted as a rule in each fragment and this was repeated with other fragments until a total 300eggs were obtained and classified into three types: immature, mature and dead ones.

Histopathological examination: Mice livers were fixed for $48 \mathrm{hr}$ in $10 \%$ buffered formalin and then embedded in paraffin. Five sections ( 5 microns in thickness) were taken from each liver specimen, each section being at a distance of at least $500 \mu \mathrm{m}$ from the preceding one (Von Lichtenberg, 1962). Sections were stained with hematoxylin and eosin (Harris, 1900) for granuloma counting and Masson trichrome stains (Masson, 1929) for collagen fibers. Lesions with a single ovum in their centers were selected for measurement (Botros et al, 1986). The greatest diameter of the lesion was obtained, then the ocular micrometer was rotated 90 degrees and diameter perpendicular to $1^{\text {st }}$ one was measured. Size of each liver granuloma was calculated from mean diameter of each lesion on assumption they were spherical (Mahmoud and Warren, 1974). For each section, granulomas were counted in five successive fields $(10 \times 10)$. 
SEM: Perfused hepatic \& porto-mesentric $S$. mansoni were collected in glutaraldehyde buffer solution $(25 \%)$ as a fixative and left overnight at $4^{\circ} \mathrm{C}$. Worms were washed off from traces of fixative by kept overnight at $4^{\circ} \mathrm{C}$ in phosphate buffer. They were passed in increasing concentrations of alcohol (30, $40, \& 50 \%$ ) each for $15 \mathrm{~min}$. Worms were left in $70 \%$ ethanol, washed twice for $30 \mathrm{~min}$ in $80 \& 90 \%$ ethanol, mounted on stainless steel holders, placed in a drier for about 30 min, and then subjected to a sputter coat of gold. Worms' parts were examined using Joel JEM-1200 SEM (Hassan et al, 2003).

Statistical analysis: Data were recorded on an investigation report form, tabulated, coded then analyzed using computer program SPSS version 16. ANOVA (analysis of variance) test used to compare between more than two groups of numerical (parametric) data and Kruskal Wallis test between more than two groups of numerical (non- parametric) data. Student's t-test used to compare between mean of two groups of numerical (parametric) data. For continuous non- parametric data; Mann-Whitney U-test were used for inter-group analysis. $\mathrm{P}$ value $<0.05$ was statistically significant \& P value $<0.01$ was highly significant in all analyses.

\section{Results}

The results showed that Nigella sativa oil treated group has a high significant effect on mean number of total mature worm burden (R 57.51\%), also prophylactic group showed significant effect on mean number of mature worms compared with the control group ( $\mathrm{R}$ $40.91 \%$ ). The highest significant decrease on mean number of total mature worm burden was observed in PZQ treated group ( $R$ $93.96 \%$ ) followed by the combination group (R93.74\%).

$N$. sativa oil showed high significant effect on reduction rate of couples whether given alone or combined with PZQ (R $68.67 \%$ \& $\mathrm{R} 91.67 \%$ respectively). Male worms were more sensitive (R 97.5\%) to combined therapy than females (R89.28\%).
Nigella sativa oil treated group showed a high significant effect on mean number of female worms (R65.92\%) more than males (R 50\%), while Non-significant reduction was observed in male and female worm burden in group received prophylactic treatment in comparison with control group, as it reached $(\mathrm{R} 47.57 \%) \&(\mathrm{R} 33.28 \%)$ respectively (Tab. 1, Fig. 1).

In oogram pattern, $N$. sativa oil treated group gave a high significant increase on mean of dead ova $(21.43 \pm 3.64)$ (which is 4.08 times as the control)and a high significant decrease on percentage of immature ova (31.0 \pm 8.49$)$, while it has no effect on mature ova $(47.57 \pm 10.7)$. In group treated with combined therapy, Nigella sativa oil proved to potentiate effect of PZQ, with the complete disappearance in immature ova $(0.0 \pm 0.0)$, highest significant increased $\%$ of dead ova $(98.2 \pm 4.02)$ and significantly decreased \% of mature ova $(1.8 \pm 4.02)$. Prophylactic group showed significantly increased percentage of dead ova (14.75 \pm 6.5$) 2.8$ times as control but, without significant effect on mature (30.5 \pm 5.26$)$ and immature ova (54.75 \pm 7.8 ) (Tab. 2, Fig. 2).

The most evident reduction in the ova count ova/gm of both intestinal and hepatic tissues was in group treated with combined therapy (R91.76\%\&R 75.76\%respectively). In $N$. sativa oil treated group, there was a high reduction in ova count in intestinal tissue ( $\mathrm{R} 81.45 \%)$ and a moderate reduction in hepatic tissue (R57.86\%) as compared with control. In the present work, lowest reduction\% in ova count/gram of hepatic tissue was in pro-phylactic group ( $\mathrm{R} 51.46 \%$ ) and reached ( $\mathrm{R} 78.76 \%$ ) in intestinal tissue (Tab. 3 , Fig 3).

The highest significant reduction in mean granuloma diameter was in combined therapy (R 27.06\%). N. sativa oil group exerted a high significant reduction of granuloma size compared with control (R 26.69\%). Least decrease in granuloma diameter was in pro phylactic group (R 14.85\%)(Tab.4, Fig 4). 
In infected untreated mice, histopathology of liver sections showed inflammatory cellular infiltrate mainly lymphocytes, with hydropic degeneration of hepatocytes and dilated sinusoids that lined by hyperplastic pigmented Von Kupffer cells. Sections of $S$. mansoni infected mice treated with therapeutic and prophylactic doses of $N$. sativa oil and scarified 8 weeks post-infection showed inflammatory cellular infiltrate mainly lymphocytes with improvement of hydropic degeneration of hepatocytes in the therapeutic group with dilated sinusoids lined by hyperplastic pigmented Von Kupffer cells. But, infected mice treated with combined therapy showed slight improvement of cloudy swelling and hydropic degeneration, fibrocellular granulomas formed mainly of monocytes and plasma cells.

SEM of $S$. mansoni untreated male showed intact tegument with normal tubercles covering its surface. Tubercles were covered with numerous intact apically directed spines with normal intertubercular spaces in between, also oral sucker and ventral sucker were intact.

SEM of the dorsal surface of adult male $S$. mansoni of prophylactic group showed extensive swelling of tubercles with complete loss of spines, wrinkles and vesicles on dor- sal tegumental surface. The oral sucker was swollen and ventral one was normal. SEM of dorsal surface of treated adult male $S$. mansoni from mice infected and treated with praziquantel showed severe reduction in number and size of tubercles, being swollen and destructed in other parts with complete loss of spines. Multiple vesicles, peeling, erosions and destruction of intertegmental spaces were seen. In adult male of $N$. sativa oil treated group, there were severe reduction in number and size of tubercles being swollen in some parts and collapsed or destructed in others with complete loss of spines and destruction of inter-tegumental spaces. There were multiple pits in tegument.

The oral and ventral suckers were retracted in both sexes with swelling of anterior part of male and constriction of worm posterior end. Female tegument showed extensive peeling and blabbing. The combined therapy changed tegumental of adults. The SEM indicated severe reduction in number and size of tubercles being swollen, collapsed and destructed in other parts of the dorsal tegumental surface of the worms with complete loss of spines and presence of multiple vesicles plus retraction in oral sucker and ventral sucker.

Table 1: Effect of Nigella sativa oil, PZQ and combination of both on mature worm burden in S. mansoni infected mice.

\begin{tabular}{|l|c|c|c|c|}
\hline \multirow{2}{*}{ Groups } & \multicolumn{4}{|c|}{ Mean mature worm burden (\%reduction) P value } \\
\cline { 2 - 5 } & Couple (R\%) & Male (R\%) & Female (R\%) & Total worms (R\%) \\
\hline Control & $6.0 \pm 1.83$ & $7.0 \pm 2.16$ & $6.25 \pm 1.26$ & $13.25 \pm 2.5$ \\
\hline \multirow{2}{*}{ Prophylactic } & $3.17 \pm 1.6(47.17 \%)$ & $3.67 \pm 1.03(47.57 \%)$ & $4.17 \pm 1.83(33.28 \%)$ & $7.83 \pm 2.23(40.91 \%)$ \\
& $\left(0.032^{*}\right)$ & $\left(0.011^{*}\right)$ & & $(0.007 * *)$ \\
\hline Praziquantel & $0.1 \pm 0.32(98.33 \%)$ & $0.30 \pm 0.48(95.7 \%)$ & $0.50 \pm 0.53(92 \%)$ & $0.8 \pm 0.92(93.96 \%)$ \\
treated & $\left(0.001^{* *}\right)$ & $(0.001 *)$ & $(0.001 * *)$ & $(0.001 * *)$ \\
\hline Nigella sativa & $1.88 \pm 0.83(68.67 \%)$ & $3.5 \pm 1.2(50 \%)$ & $2.13 \pm 0.99(65.92 \%) \#$ & $5.63 \pm 1.69(57.51 \%)$ \\
treated & $\left(0.001^{* *}\right)$ & $\left(0.004^{* *}\right)$ & $(0.001 * *)$ & $\left(0.001^{* *)}\right.$ \\
\hline \multirow{2}{*}{ Combined } & $0.50 \pm 0.55(91.67 \%)$ & $0.17 \pm 0.41(97.5 \%)$ & $0.67 \pm 0.52(89.28 \%)$ & $0.83 \pm 0.75(93.74 \%)$ \\
& $\left(0.009^{* *}\right)$ & $\left(0.006^{* *}\right)$ & $\left(0.008^{* *}\right)$ & $\left(0.009^{* *}\right)$ \\
\hline
\end{tabular}

N. sativa oil prophylactic dose: $(1.14 \mathrm{~g} / \mathrm{kg})$ daily for 2 weeks before infection.

Nigella sativa oil therapeutic dose: $(1.14 \mathrm{~g} / \mathrm{kg})$ daily for 4 weeks starting from $2^{\text {nd }}$ day post infection.

Praziquantel dose: $(500 \mathrm{mg} / \mathrm{Kg})$ for 2 successive days at $6^{\text {th }}$ week of infection.

Combined therapy: Nigella sativa oil therapeutic dose + praziquantel dose.

*P value <0.05: Significant difference between treated groups versus control group.

$* * \mathrm{P}$ value $<0.01$ : High significant difference between treated groups versus control group.

\# Nigella sativa group showed significant difference versus prophylactic group $\left(\mathrm{P}\right.$ value $\left.=0.037^{*}\right)$ 
Table 2: Effect of N. sativa oil, PZQ and both on oogram pattern in intestinal segments of S. mansoni infected mice.

\begin{tabular}{|l|c|c|c|}
\hline \multirow{2}{*}{ Groups } & \multicolumn{3}{|c|}{ Egg types Mean \pm SD P value } \\
\cline { 2 - 4 } Control & Mature & Dead & Immature \\
\hline Prophylactic & $32.25 \pm 10.05$ & $5.25 \pm 1.71$ & $62.5 \pm 9.43$ \\
\hline Praziquantel treated & $30.5 \pm 5.26$ & $14.75 \pm 6.5\left(0.03^{*}\right)$ & $54.75 \pm 7.8$ \\
\hline Nigella sativa oil treated & $47.57 \pm 1.93\left(0.004^{* *}\right)$ & $98.1 \pm 2.13\left(0.001^{* *}\right)$ & $0.10 \pm 0.32\left(0.001^{* *}\right)$ \\
\hline combined group & $1.8 \pm 4.02\left(0.015^{*}\right)$ & $21.43 \pm 3.6 \#\left(0.001^{* *}\right)$ & $31.0 \pm 8.49\left(0.001^{* *}\right)$ \\
\hline \multicolumn{4}{|c|}{ \#N. sativa group showed significant difference versus prophylactic group (P value $\left.=0.008^{* *}\right)}$. \\
\hline
\end{tabular}

Table 3: Effect of $N$. sativa oil, PZQ and both drugs on mean number of (ova/gram) on hepatic tissue and intestinal tissue of S. mansoni infected mice.

\begin{tabular}{|l|c|c|}
\hline Groups & No of ova/gram hepatic tissue (R\%) P value & No of ova/gram intestinal tissue (R\%) P value \\
\hline Control & $8250.0 \pm 5881.89$ & $25990.0 \pm 22291.55$ \\
\hline Prophylactic & $4004.83 \pm 1613.44(51.46 \%)$ & $5520.0 \pm 2131.5(78.76 \%)$ \\
\hline Praziquantel treated & $2024.0 \pm 845.7(75.47 \%) 0.005^{* *}$ & $2339.0 \pm 1036.78(91 \%) 0.004^{* *}$ \\
\hline Nigella sativa oil treated & $3476.33 \pm 2396.61(57.86 \%)$ & $4820.0 \pm 2427.15(81.45 \%) 0.019^{*}$ \\
\hline Combined & $1999.83 \pm 1184.12(75.76 \%) 0.032^{*}$ & $2141.67 \pm 633.19(91.76 \%) 0.027^{*}$ \\
\hline
\end{tabular}

Table 4: Effect of N.sativa oil, PZQ and combination of both drugs on mean number and diameter of hepatic granuloma in S. mansoni infected mice.

\begin{tabular}{|l|l|l|}
\hline \multirow{2}{*}{ Groups } & Mean hepatic granuloma $(\mathrm{P}$ value $)$ \\
\cline { 2 - 3 } & Mean n. of granuloma $(\mathrm{R} \%)$ & Mean diameter of granuloma in $(\mu \mathrm{m})(\mathrm{R} \%)$ \\
\hline Control group & $10.5 \pm 1.19$ & $246.82 \pm 37.65$ \\
\hline Prophylactic group & $6.53 \pm 2.0(37.81 \%) 0.008^{* *}$ & $210.16 \pm 33.34(14.85 \%)$ \\
\hline Praziquantel treated group & $4.13 \pm 2.75(60.67 \%) 0.001^{* *}$ & $197.7 \pm 25.44(19.9 \%) 0.022^{*}$ \\
\hline Nigella sativa oil treated group & $5.14 \pm 2.29(51.05 \%) 0.002^{*}$ & $180.94 \pm 22.57(26.69 \%) 0.003^{* *}$ \\
\hline combined group & $3.17 \pm 1.17(69.81 \%) 0.001^{* *}$ & $180.04 \pm 43.16(27.06 \%) 0.036^{*}$ \\
\hline
\end{tabular}

\section{Discussion}

Nigella sativa oil is one of the promising drugs of herbaceous plant with an antiSchistosoma effect (Ali et al, 2016). Substances having antioxidant, antimicrobial or cytotoxic other than genotoxic and mutagenic potentials are safe for human consumption (Islam, 2016).

The oil contains significant (10\%) amounts of fatty acid ethyl esters. On storage, thymoquinone turns into the dithymoquinonene and higher oligocondensation products. Fatty oil rich in unsaturated fatty acids, such as linoleic acid (50 60\%), oleic acid (20\%), eicodadienoic acid (3\%) and dihomolinoleic acid $(10 \%)$ are also find in the seeds. Saturated fatty acids (stearic acid and palmitic acid) amount is approximately $30 \%$ or less. Also, parts of the essential oil, mostly thymoquinone that is responsible for an aromatic flavor. The oil contains d -limonene, carvone, and a carbonyl compound, nigellone (Ziaee et al, 2012). In the present study, $N$. sativa oil proved to have a nonantagonistic effect on PZQ. This was evident in group treated by combined therapy as reduction rate of total mature worm burden more or less the same as group treated by PZQ. These data were in agreement with Mahmoud et al. (2002) who reported more reduction in mean number of total worm from $98 \%$ to $99 \%$ when treated with increased dose of $N$. sativa oil in combination with PZQ. Also, N. sativa oil treated group gave a high significant effect on mean number of total mature worm burden. These data more or less went with Ali et al. (2016) who reported that the total worm burden reduction percentage increased from 45 to 57 in group treated with $N$. sativa oil at a dose of $250 \mu 1 / \mathrm{kg} /$ body wright/day after day from the $5^{\text {th }}$ week to $7^{\text {th }}$ week post-infection. This agreed with the reports of El shenawy et al. (2008) and Adamu and Dukku (2009). N. sativa oil affected the schitosome worms by altering their level of various eicosanoids that in turn enhanced the immune system to cause disintegration of the worms or at least damaged by stop maturation and hence prevent egg-laying (Mahmoud et al, 2002).

Moreover, N. sativa oil showed high significant effect on reduction rate of couples whether given alone or in combination with PZQ. This also agreed with Yarnell and 
Abascal (2011) who noticed separation of the couple after incubation with black seed extract in vitro while the control untreated paired worms remain coupled with vigorous activity. Moreover, Nigella sativa oil treated group showed more reduction on mean number of female worm burden than reduction in male worm burden. However, Ali et al. (2016) who reported more decrease on male worm burden than female one. This difference in sensitivity of both sexes might be due to differences in $S$. mansoni strain used in each study (El-Lakkany et al, 2011). Also, these last authors reported that female worms alone were significantly more susceptible than male worms to goyazensolide killing. The oogram pattern for enumeration of the various egg types prove to be an easy and reliable method of evaluating the therapeutic value of anti-schistosomal drugs (Pellegrino et al, 1977).

In the current study, $N$. sativa oil treated group showed a high significant increase in percentage of dead ova and a high significant decrease on percentage of immature ova. This result greed with Muriel (2009) who found that $N$. sativa oil alone significantly increased the number of dead ova while hardly affecting the immature ova.

In the present study, Praziquantel gave a high significant decrease on percentage of immature $(0.10 \pm 0.32)$ and mature ova (1.8 \pm 1.93$)$.

This result agreed with Khalil (2000) who stated that PZQ treatment showed a complete disappearance of all immature ova from the wall of the intestine, a reduction in the number of mature ova and a four folds increase in dead ova .In the group treated with combined therapy, Nigella sativa oil proved to potentiate the effect of PZQ, as there was complete disappearance in the immature ova ,also, it has the highest significant increase in the percentage of dead ova and it significantly decreases the percentage of mature ova.

Also, combination of Nigella sativa oil with aqueous garlic extract led to increase the number of dead eggs and enhanced maturation of Schistosoma ova (ElShenawy et al, 2008). Also, they recorded a significant reduction in number of eggs/g liver in groups treated with Nigella sativa oil or its combination with garlic extract. Ali et al. (2016) stated that use of Nigella sativa oil alone exerted a significant effect on ova count in liver and intestinal tissue.

In the present study, the most evident reduction in the mean number of hepatic granuloma per $5 /$ low power fields was in group treated with combined therapy. In $N$. sativa oil, treated group there was a moderate reduction on mean number of hepatic granuloma while, the lowest percentage of reduction was in prophylactic group. The number of granuloma coincided with their effect in increasing dead ova count compared to positive control group.

Mahmoud et al. (2002) reported that $N$. sativa oil suppressed the size of the developing liver granuloma in a dose dependent manner, being reduced $15.8 \%$ and $24.3 \%$ for the doses $2.5 \mathrm{ml} \& 5 \mathrm{ml}$ respectively. Also, Sheir et al. (2015) found that combination of black seed oil and Artemether and/or PZQ treatments recorded marked reduction of hepatic granuloma diameter $35.42 \%$ \& $32.23 \%$, respectively. Soliman and El-Shenawy (2003) who reported that Nigella sati$v a$ oil produced less pathological lesions in the liver of $S$. mansoni infected mice, especially the inflammatory reactions that mediate both granuloma diameter and number.

No doubt, black seed oil and thymoquinie (TQ) have strong anti-inflammatory effect, as they were found to reduce the synthesis of nitric oxide, interleukin-1, cyclooxygenase (COX)-1, COX-2 and histone deacetylase along with other pro-inflammatory mediators such as interleukin-1 $\beta$, interleukin-6, tumor necrosis factor- $\alpha$, interferon- $\gamma$ and prostaglandin (Ahmad et al, 2013).

In the current work, hepatic tissue from mice infected treated with $N$. sativa oil post infection, showed mild hydrobic degeneration and slightly dilated sinusoids. The two 
types of granulomas were observed, wellformed cellular granulomas were present in hepatic lobules and the fibrocellular granulomas with less inflammatory cells formed mainly of lymphocytes, eosinophils and plasma cells that becomes smaller than control-infected group.

These results coincided with Alenzi et al. (2010) who recorded that the Nigella sativa seed are reported to possess potent antioxidant effects. The effect of Nigella sativa on $S$. mansoni infected liver may be due to its important role of antioxidant effect of the oxidative stress in mediating liver injury in schistosomiasis, which increases the production of reactive oxygen intermediates by eosinophils and macrophages at the site of the granulomatous inflammation (McCormick et al, 1996).

The hepatic schistosomiasis, or schistosomal hepatopathology, was the commonest form of chronic disease and usually resulted from heavy $S$. mansoni infection (Lambertucci et al, 2001). The use of $N$. sativa oil, an immunomodulating agent, as an assistant to chemotherapy may be effective in augmenting the reduction of immunopathology, PZQ is active against all schistosome species infecting humans, an important feature, especially in those areas where more than a single species is present, typically in Africa where $S$. mansoni and S. haematobium are often co-endemic (Cioli et al, 2012). In the present study, combined therapy of Nigella sativa oil and PZQ, Liver cells showed slight improvement of cloudy swelling and hydropic degeneration, fibrocellular granulomas formed mainly of monocytes and plasma cells were observed. SEM played an important role in elucidating the detailed morphology and different alterations of the S. mansoni tegument allowing the interpretation of its functionality (El-Shabasy et al, 2015). The surface topography of schistosomes have been investigated to evaluate the antischistosomal activities of several compounds, since the tegument of schistosomes is an important target for such drugs ( $\mathrm{Ji}$ raungkoorskul et al, 2005; Mostafa, 2005). The current study proved alterations in the tegumental surface of mature S. mansoni following $N$. sativa oil treatment in vivo by using SEM. Treatment with $N$. sativa oil alone or combined with PZQ showed structural changes in tegument of the adult treated worms by reduction of number and size of tubercles being swollen in some parts and collapsed in other parts and retraction of both oral and ventral suckers. The edema also involved the tubercles, which appeared thickened with raised knobs. These results agreed with Mostafa (2005) who found that the tegument of worms developed in mice treated with black-seed oil showed moderate structural changes, since the tubercles on the dorsal surface of the male showed partial loss of spines. The dorsal surface of the tegument of the adult worm in the prophylactic group showed extensive swelling of tubercles with complete loss of spines, wrinkles and vesicles as well as obliteration and swollen suckers which coincided with Mostafa and Soliman (2002) who found that treatment with black seed oil from day zero of infection showed extensive loss of spines with small sized tubercles and edema of the inter-tubercular regions. Tubercle distortions caused inability of worm to adhere to host's walls of blood vessels that almost led schistosome to be dislodged and transported in blood stream from mesenteric veins to portal vein and intravenous hepatic capillaries and lodged in liver (Mehlhorn et al, 1981).

\section{Conclusion}

Based on the outcome of this study, Nigella sativa oil proved to have a potential bioactivity against $S$. mansoni adult stages and its potentiality in improving hepatic pathology. Efficacy of N. sativa to postpone progression in chronic liver diseases must be considered as preventive medicine in patients with hepatic disorders. Antioxidant and antiinflammatory properties are features of preventing and protected liver from injury 


\section{References}

Abdel Hady, NM, El-Sherbibi, GT, Morsy, T A, 2008: Treatment of Toxoplasma gondii by two Egyptian herbs. J. Egypt. Soc. Parasitol. 38, 3:1024-5.

Adamu, SU, Dukku, UH, 2009: Antischistosomal Effect of Seed Oil of Nigella sativa (Black Caraway) on Schistosoma mansoni. BRI J. 1, 1:50-53.

Agrawal, R, Kharya, MD, Shrivastava, R, 1979: Antimicrobial and anthelmintic activities of the essential oil of Nigella sativa Linn. Indian J. Exp. Biol.17:1264-5.

Ahmad, A, Husain, A, Mujeeb, M, Khan, S A, Najmi, AK, Siddique, NA, et al, 2013: A review on therapeutic potential of Nigella sativa: A miracle herb. Asian Pac. J. Trop. Biomed. 3, 5:337-52.

Al-Ali, A, Alkhawajah AA, Randhawa, MA, Shaikh, NA, 2008: Oral and intra-peritoneal $\mathrm{LD}_{50}$ of thymoquinone, an active principle of Nigella sativa, in mice and rats. J. Ayub .Med. Coll. Abbottabad. 20, 2:25-7.

Ali, M, Abou-Eldahab, M, Mansour, HA, Nigm, A, 2016: Schistosoma mansoni: Anti-parasitic effects of orally administered Nigella sati$v a$ oil and /or Chroococcus turgidus extract. Acta Biol. Hungarica 67, 3:247-60.

Alenzi, FQ, El-Bolkiny, Yel-S, Salem, ML, 2010: Protective effects of Nigella sativa oil and thymoquinone against toxicity induced by the anticancer drug cyclophosphamide. Br. J. Biomed. Sci. 67, 1:20-8.

Bakathir, HA, Abbas, NA, 2011: Detection of the antibacterial effect of Nigella sativa ground seeds with water. Afr. J. Tradit. Compl. Altern. Med. 8, 2:159-64.

Barakat, EM, El-Wakeel, LM, Hagag, RS, 2013: Effects of Nigella sativa on outcome of hepatitis C in Egypt. Wd. J .Gastroenterol. 19: 2529-36.

Botros, S, El-Badawy, N, Metwally, AA, Khayyal, MT, 1986: Studies of some Immunological properties of Praziquantel in experimental schistosomiasis mansoni. Ann. Trop. Med. Parasitol. 80, 2:189-96.

Bourgou, S, Pichette, A, Marzouk, B, Legault, J, 2012: Antioxidant, anti-inflammatory, anticancer and antibacterial activities of extracts from Nigella sativa (Black Cumin) plant parts.

J. Food Biochemist. 36:539-46.

Castro, AP, Mattos, ACA, Souza, RLM, Mar- cos, MJ, Santos, MH, 2013: Medicinal plants and their bioactive constituents: A review of bioactivity against Schistosoma mansoni. J. Med. Plants Res. 7, 21:1515-22.

Chakrabarty, A, Emerson, MR, LeVine, SM, 2003: Heme-oxygenase- 1 in SJL mice with experimental allergic encephalomyelitis. Mult. Scler. 9:372-81

Cioli, D, Basso, A., Valle, C., Pica-Mattoccia, L, 2012: Decades down the line: Viability of praziquantel for future schistosomiasis treatment. Expert. Rev. Anti-infect. Ther. 10, 8:835-7.

Duvall, RH, De Witt, WB, 1967: An improved perfusion technique for recovering adult schistosomes from laboratory animals. Am. J. Trop. Med. Hyg. 16:483-6.

El-Lakkany, NM, EL-Din, SHS, Sabra, AA, Hammam, OA, 2011: Pharmacodynamics of Mefloquine and Praziquantel combination therapy in mice harboring juvenile and adult Schistosoma mansoni. Mem. Inst. Oswaldo Cruz 106, 7:814-22.

El-Shabasy, EA, Reda, ES, Abdeen, SH, Said, AE, Ouhtit, A, 2015: Transmission electron microscopic observations on ultrastructural alterations in Schistosoma mansoni adult worms recovered from C57BL/6 mice treated with radiation attenuated vaccine and/or Praziquantel in addition to passive immunization with normal and vaccinated rabbit sera against infection. Parasitol. Res. 114, 4:1563-80.

El-Shenawy, NS, Soliman, MF, Reyad, SI, 2008: The effect of antioxidant properties of aqueous garlic extract and Nigella sativa as antischistosomiasis agents in mice. Rev. Inst. Med. Trop. Sao Paulo 50:29-36.

El-Tahir, KEH, Bakeet, DM, 2006: The Black Seed Nigella Sativa Linnaeus: A mine for multi cures: A plea for urgent clinical evaluation of its volatile oil. JTU Med. Sci.1, 1:1-19.

Goreja, WG, 2003: Black Seed: Nature's Miracle Remedy. New York, NY7 Amazing Herbs Press.

Harris, HF, 1900: On rapid conversion of hem atoxylin into staining reactions. J. Applied Microscopic Laboratory Methods 3:777. Quoted from: Theory and Practice of Histological Techniques. Bancroft, G.D, Sterens, A. (Eds.). 1980. London. New York.

Hassan, MM, El-Motaiem, M, Afifi, H, Abaza, B, El-Shafei, M Massoud, AM, 2003: In vitro effect of Mirazid on Schistosoma mansoni 
worms. J. Egypt. Soc. Parasitol. 33, 3:999-1008. Islam, MT, 2016: A comprehensive and up-dated review on the pharmacological activities and phytochemistry of Nigella sativa L .Adv. Biomed. Pharma. 3, 6:408-24.

Jiraungkoorskul, W, Sahaphong, S, Sobhon, $\mathbf{P}$, Riengrojpitak, S, Kangwanrangsan, N, 2005: Effects of praziquantel and artesunate on the tegument of adult Schistosoma mekongiharbored in mice. Parasitol. Int. 54:177-83.

Khalil, SS, 2000: On the schistosomicidal effect of Triclabendazole an experimental study. J. Egypt. Soc. Parasitol. 30, 3:799-808.

Lambertucci, JR, Cota GF, Pinto-Silva RA, Serufo JC, Gerspacher-Lara R, et al, 2001: Hepatosplenic schistosomiasis in field-based studies: a combined clinical and sonographic definition. Mem. Inst. Oswaldo Cruz 96:147-50.

Mahmoud, AAF, Warren, KS, 1974: Anti-inflammatory effects of Tarteremetric and Nirigdazole suppression of schistosoma egg granuloma. J. Immunol. 112:222-8.

Mahmoud, MR, El-Abhar, HS, Saleh, S, 2002: Effect of Nigella sativa oil against the liver damage induced by Schistosoma mansoni infection in mice. J. Ethnopharmacol. 79:1-11.

Masson, P, 1929: Some histological methods, trichrome staining and their preliminary technique. Bull. Int. Ass. Med. 12:75-80.

McCormick, ML, Metwalli, A, Railsback, M A, Weinstock, JV, Britigan, BE, 1996: Eosinophils from schistosome-induced hepatic granulomas produce superoxide and hydroxyl radical. J. Immunol. 157:5009-15.

Mehlhorn, H, Becker, B, Andrews, P, Thomas, H, Frenkel, J, 1981: In vivo \&in vitro experiments on the effects of praziquantel on Schistosoma mansoni: A light and electron microscopic study. Arzneimittelforschung .31:544-54.

Mohamed, AM, Metwally, NM, Mahmoud, S S, 2005: Nigella sativa seeds against Schistosoma mansoni different stages. Mem. Inst .Oswaldo Cruz 100, 2:205-11.

Mostafa, OMS, 2005: Effects of sedr honey and/or black-seed oil on Schistosoma mansoni in albino mice: parasitological, biochemical and scanning electron microscopical studies. Egypt. J. Zool. 45:449-69.

Mostafa, OMS, Soliman, MI, 2002: Experimental use of black-seed oil against Schistosoma mansoni in albino mice. II. Surface topography of adult worms. Egypt. J. Med. Lab. Sci. 11, 1:79-85.
Muriel, P, 2009: Roles of free radicals in liver diseases. Hepatol. Int. 3:526-36.

Nickavar, B, Mojab, F, Javidnia, K, Amoli, M A, 2003: Chemical composition of the fixed and volatile oils of Nigella sativa $\mathrm{L}$. from Iran. Z .Naturforsch C. 58, 9/10:629-31.

Okeola, VO, Adaramoye, OA, Nneji, CM, Falade, CO, Farombi, EO, Ademowo, OG, 2011: Antimalarial and antioxidant activities of methanolic extract of Nigella sativa seeds (black cumin) in mice infected with Plasmodium yoellinigeriensis. Parasitol. Res. 108:1507-12.

Pellegrino, J, Lima-Casta, FF, Carlos, MA, Mello, RT, 1977: Experimental chemotherapy of S. mansoni. Parasitenkd. 52:151-68.

Pellegrino, J, Oliveira, CA, Faria, J, Cunha, AC, 1962: New approach to the screening of drugs in experimental schistosomiasis mansoni in mice. Amer. J. Trop. Med. Hyg.11:202-15.

Queiroz, EF, Wolfender, JL, Hostettmann, K, 2009: Modern approaches in the search for new lead antiparasitic compounds from higher plants. Curr. Drug Targets 10, 3:202-11.

Salem, ML, 2005: Immunomodulatory and therapeutic properties of the Nigella sativa L. seed. Int. Immunopharmacol. 5, 13/14:1749-70.

Sharaf EL-Din, KM, 2015: Physiological impact of ginger, Zingiber officinale \& black seed oil, Nigella sativa L. as medicinal plants in gamma-irradiated rats. Egypt. J. Exp. Biol. (Z), 11: 185-92.

Shariff, HA, Ajmi, RN, Jasim, A, 2011: Effect of Plant extract of Nigella sativa on the effectiveness of the parasite Entamoeba histolyticain patients from Al-Hammar Marsh Iraq, Al-Nasiriyah. AJPS 9, 1:105-12

Sheir, SK, Maghraby AM, Mohamed, AH, Osman, GY, Al-Qormuti, S, 2015: Immunomodulatory and ameliorative role of Nigella sativa oil on Schistosoma mansoni infected mice. CJPAS. 9:3345-55.

Soliman, MFM, El-Shenawy, NS, 2003: Evaluation of the protective effect of two antioxidative agents in mice experimentally infected with Schistosoma mansoni: Haematological and histopathological aspects. Pak. J. Boil. Sci. 6:88797.

Tonkal, AMD, 2009: In Vitro anti-trichomonal Effect of Nigella Sativa aqueous extract and wheat germ agglutinin. J. Med. Sci. 16, 2:17-34 Von Lichtenberg, F, 1962: Host response to eggs of S. mansoni. I. Granuloma formation in 
unsensitized laboratory mouse. Am. J. Pathol. 41:711-31.

WHO, 2012: Prevention and control of schistosomiasis and soil-transmitted helminthiasis: Report of a WHO Expert Committee. WHO Technical Report Series Geneva, No. 912.
Yarnell, E, Abascal, K, 2011: Nigella sativa: holy herb of the middle East. Altern. Compl.

Therap. 17:99-105.

Ziaee, T, Moharreri, N, Hosseinzadeh, H, 2012: Review of pharmacological and toxicological effects of Nigella sativa and its active constituents. J. Medicinal Plants 11:16-42.

\section{Explanation of figures}

Fig.1: Effect of Nigella sativa oil, PZQ and combination of both drugs on mature worm burden in $S$. mansoni infected mice.

Fig. 2: Effect of $N$. sativa oil, PZQ and combination of both drugs on oogram pattern in intestinal segments of $S$. mansoni infected mice.

Fig. 3: Effect of $N$. sativa oil, PZQ and both drugs on mean ova/gram in both hepatic tissue and intestinal tissue of $S$. mansoni infected mice.

Fig. 4: Effect of N. sativa oil, PZQ and combination of both drugs on number (A) and diameter (B) of hepatic granuloma in $S$. mansoni in-

fected mice

Fig. 5: Liver section of Praziquantel treated group. a- Mild infiltrate of hepatic parenchyma with inflammatory cells mainly lymphocytes (yellow arrow) and slightly dilated sinusoids that lined by hyperplastic pigmented Von kupffer cells (red arrow), hepatocytes show slight hydropic degeneration (H \& E, X400), b- Well-demarcated medium sized fibrocellular granuloma with several layers of concentrically arranged collagenous fibrous tissue (green arrow) surrounding degenerated ovum (red arrow) with rim of inflammatory cells, mainly eosinophils and lymphocytes (yellow arrow) (H \& E, X100).

Fig. 6: Photomicrograph of liver section of Nigella sativa oil treated group. c- Scanty inflammatory cellular infiltrate of the liver parenchyma mainly lymphocytes (black arrow), mild hydrobic degeneration (yellow arrow) and slightly dilated sinusoids. (H\&X stain) (X400), d- Small sized cellular granuloma (yellow arrow) consisting of inflammatory cells (mainly lymphocytes) surrounding single egg with degenerated miracidium (red arrow) (H \& E, X100)

Fig. 7: Liver section of prophylactic group, e- Hydropic degeneration and moderate dilatation of sinusoids with moderate inflammatory infiltrate (red arrow) (H \& E, X400), f- Cellular granuloma (yellow arrow) around single ova (red arrow) (H \& E, X100).

Fig. 8: SEM of praziquantel treated group: dorsal surface of treated adult male $S$. mansoni with severe reduction in number and size of tubercles being swollen, collapsed and destructed in other parts of dorsal tegumental surface of worms with complete loss of spines (SL), multiple vesicles (V). (x 2000).

Fig. 9: SEM of $N$. sativa oil treated group, a-dorsal surface of treated adult male $S$. mansoni showed severe reduction in number and size of tubercles being swollen in some parts and collapsed or destructed (TD) in other parts of dorsal tegumental surface with complete loss of spines (SL), b- dorsal surface showed extensive destruction of the tubercles (TD) with complete loss of spines in some, multiple vesicles (V) of dorsal tegumental surface $(\mathrm{x} 2000)$.
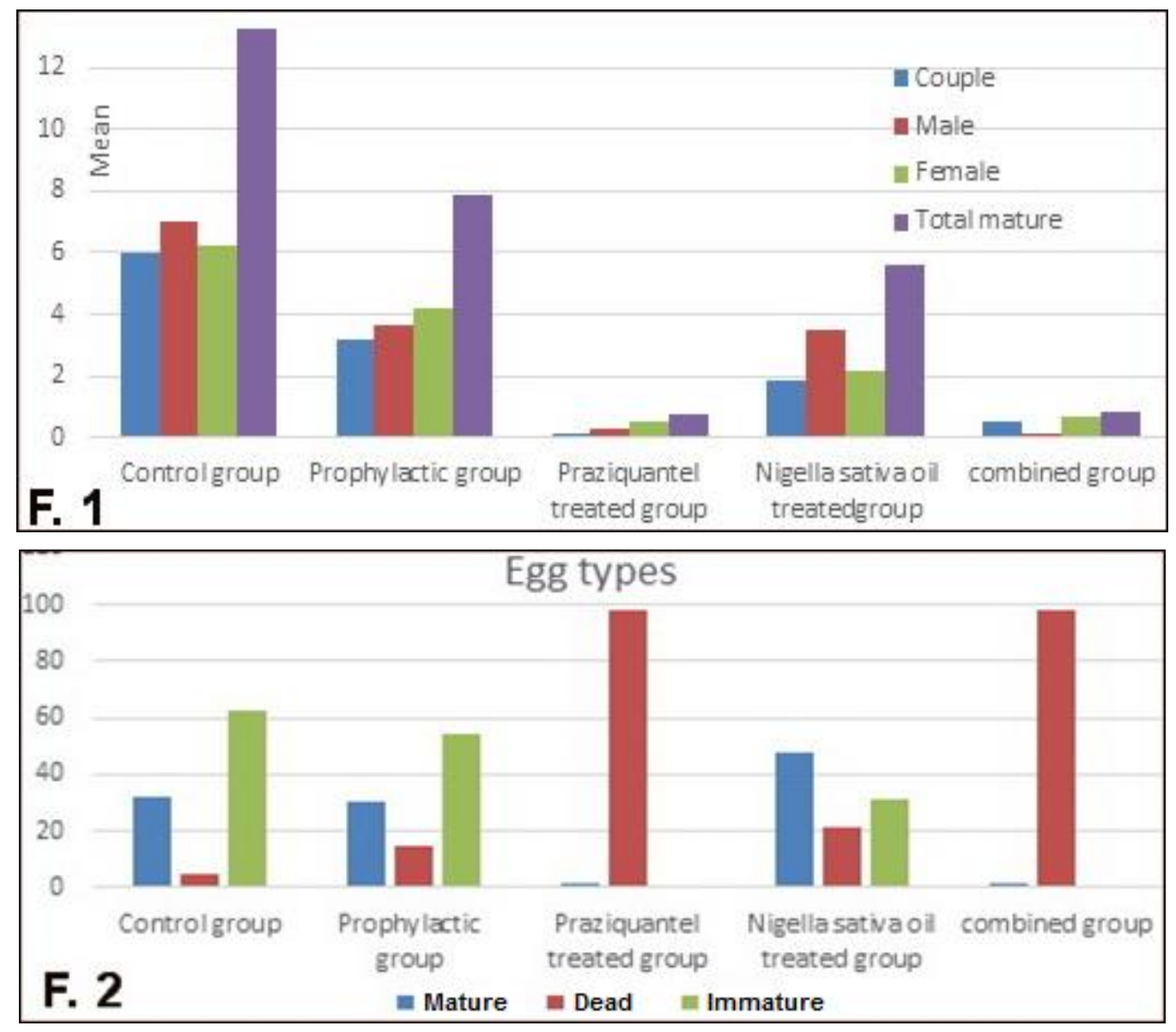

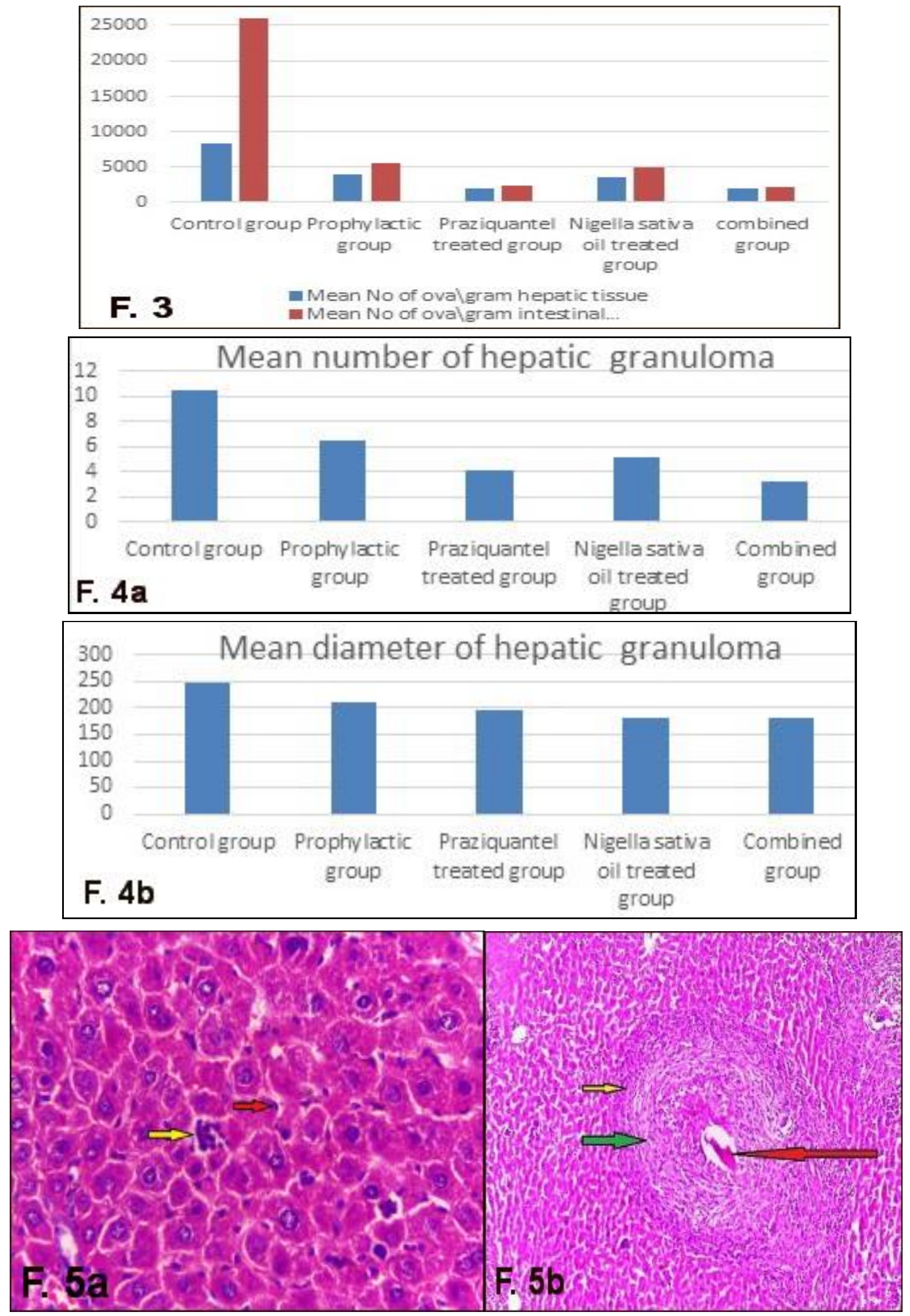

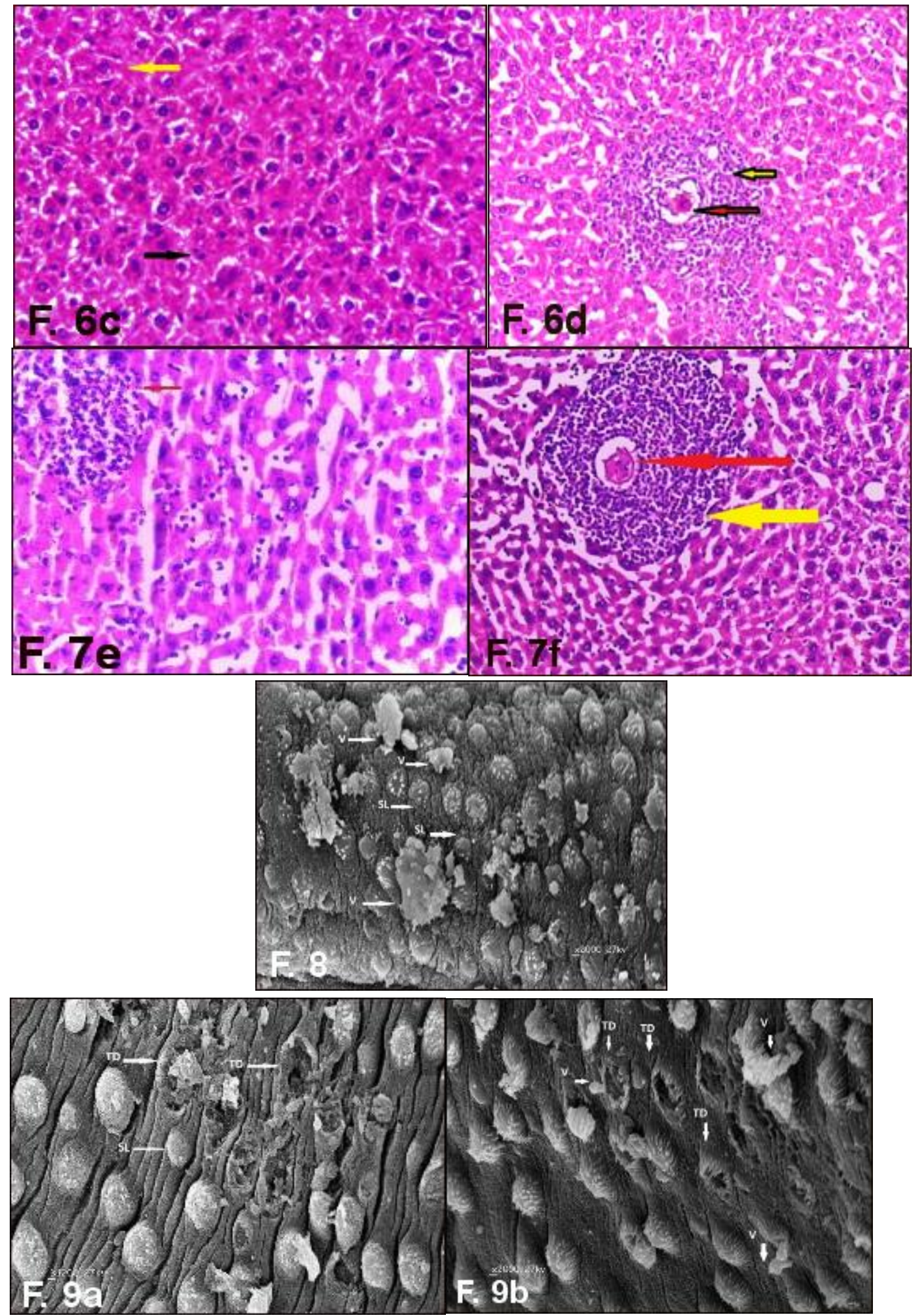